\title{
Dissolution behavior of metal oxide nanomaterials in cell culture medium versus distilled water
}

\author{
Mary-Luyza Avramescu • Marc Chénier • \\ Srijanani Palaniyandi • Pat E. Rasmussen (D)
}

Received: 30 June 2020 / Accepted: 7 July 2020 / Published online: 23 July 2020

(C) The Author(s) 2020

\begin{abstract}
Solubility is a key criterion used in the hazard assessment of metal oxide-engineered nanomaterials (ENMs). The present study investigated solubility of $\mathrm{CuO}, \mathrm{NiO}$, and $\mathrm{TiO}_{2}$ ENMs compared with their bulk analogues in two aqueous media: water and Dulbecco's modified Eagle's medium (DMEM). Particle size distributions were characterized using dynamic light scattering (DLS) and tunable resistive pulse sensing (TRPS). After centrifugal separation, the dissolved metal fraction was quantified using inductively coupled plasma optical emission spectroscopy (ICP-OES). Overall, solubility of the metal oxides decreased in the order $\mathrm{CuO} \geq \mathrm{NiO}>$ $\mathrm{TiO}_{2}$ in both media, with each ENM displaying higher solubility than its bulk analogue. However, the metal oxide ENMs responded differently to the two aqueous media, when comparing their solubility using a low initial concentration $(10 \mathrm{mg} / \mathrm{L})$ versus a high initial concentration $(100 \mathrm{mg} / \mathrm{L})$. In DMEM, both nano-CuO and nano-NiO displayed increased solubility at the higher initial concentration by 3.8 -fold and 1.4 -fold,
\end{abstract}

Electronic supplementary material The online version of this article (https://doi.org/10.1007/s11051-020-04949-w) contains supplementary material, which is available to authorized users.

M.-L. Avramescu • M. Chénier · P. E. Rasmussen Environmental Health Science and Research Bureau, Environmental and Radiation Health Sciences Directorate, HECSB, Health Canada, Ottawa, ON K1A0K9, Canada

S. Palaniyandi · P. E. Rasmussen $(\bowtie)$

Faculty of Science, University of Ottawa, Ottawa, ON K1N 6N5, Canada

e-mail: pat.rasmussen@canada.ca respectively. In water, this trend was reversed, with both nano- $\mathrm{CuO}$ and nano-NiO displaying increased solubility at the lower initial concentration by 3.3 -fold and 1.2fold, respectively. Interestingly, solubility trends displayed by nano- $\mathrm{TiO}_{2}$ were the opposite of those displayed by nano- $\mathrm{CuO}$ and nano-NiO. In DMEM, nano- $\mathrm{TiO}_{2}$ displayed decreased solubility at the higher initial concentration ( 0.3 -fold), whereas in water, nano$\mathrm{TiO}_{2}$ displayed increased solubility at the higher initial concentration (5.5-fold). These results show the importance of evaluating the solubility of ENMs in biologically relevant fluids at concentrations that correspond to toxicity assays, for the purposes of read-across and grouping ENMs.

Keywords Nanoparticles · Titanium dioxide - Anatase · Rutile · Copper oxide · Nickel oxide · Nanotoxicology · Cell culture medium $\cdot$ Environmental and Health Issues

\section{Introduction}

Metal oxide-engineered nanomaterials (ENMs) are widely used in consumer products (e.g., fillers, pigments, UV absorption filters, and semi-conductors). It is known that the distinct physical-chemical properties of ENMs (size, shape, surface area, surface charge, and solubility) influence their toxicological effects (OECD 2012). Among these, solubility is a key parameter affecting biopersistence and biokinetics of ENMs which, in turn, influence their toxicity (Arts et al. 2015a; Oberdörster and Kuhlbusch 2018; Sohal et al. 2018; 
ISO 2017; OECD 2018). International efforts are underway to group ENMs for hazard assessment, and solubility has been identified as an important screening criterion (Arts et al. 2015a; Landsiedel et al. 2017; OECD 2015). The DF4nanoGrouping initiative (Arts et al. 2015a, b) uses a water solubility threshold of $100 \mathrm{mg} / \mathrm{L}$ to classify ENMs as soluble (group 1) or biopersistent (groups 2, 3, and 4). A similar grouping approach was used by OECD (OECD 2015), based on percentage solubility (\% of total metal concentration) as the screening criterion, and consisting of four categories: high $(>70 \%)$, moderate $(10-70 \%)$, low $(1-10 \%)$, and negligible $(<1 \%)$ solubility.

Studies have shown that inhalation of metal oxide ENMs can lead to lung inflammation, the severity of which is property-specific (Nel et al. 2006; Duffin et al. 2007; Monteiller et al. 2007; Rahman et al. (2017) in the case of $\mathrm{TiO}_{2}$ ENMs. Knowledge of their dissolution behavior is critical to establish the true biological effect of metal oxide ENMs because adverse effects have been attributed not only to the nanoparticles (NPs) themselves but also to the metal released to the surrounding aqueous media (Alkilany et al. 2016; Arts et al. 2015a; Cho et al. 2011; Cho et al. 2012; Koltermann-Jülly et al. 2018; Krug 2014; Rahman et al. 2017; Semisch et al. 2014; Zhang et al. 2012). Solubility also affects ENM stability in biological media (e.g., cell culture media), influencing the formation of agglomerates/aggregates that have varying sedimentation rates, which in turn influences their interaction with the cells and biological response (Alkilany et al. 2016; Cohen et al. 2013; Guggenheim et al. 2018; Oberdörster and Kuhlbusch 2018; OECD 2012).

A key challenge in the context of nanotoxicology is the difficulty in designing experiments capable of determining the degree to which the observed toxicity is caused by the metal oxide NPs, aggregates/ agglomerates of the NPs, or by the release of metal ions (Misra et al. 2012a; Alkilany et al. 2016). Recent studies that have tackled the debate as to whether toxic effects are due to NPs themselves or the released ions (Wang et al. 2016; Jeong et al. 2018; Strauch et al. 2020) all emphasize the importance of understanding the solubility of metal oxide NPs in the relevant test media, on a case-by-case basis. This aspect is poorly understood due to the complex dissolution behavior of ENMs and their interactions with components of the test medium, and the practical difficulty of evaluating changes in dissolution over the timescale of the exposure (Misra et al. 2012a). Rapid agglomeration or aggregation means that ENMs do not retain their primary particle size when dispersed in test media, and sonication protocols must be optimized on a case-by-case basis in order to ensure that ENMs are dispersed properly (Chowdhury et al. 2010; Cohen et al. 2013; Deloid et al. 2017; OECD 2012; OECD 2017; Taurozzi et al. 2013). Hull et al. (2012) expressed concern that, at the time of writing, only $8 \%$ of previous studies had conducted physicalchemical characterization in the experimental media used to measure a toxicological response, and none had reported the fraction of dissolved ions present. Similar concerns were later reiterated by Alkilany et al. (2016) who found that colloidal stability of NPs in test media was usually ignored, despite the critical importance of this parameter in nanotoxicology, and by Hansen et al. (2017) who reported that only a fraction of previous OECD studies had characterized the target NPs in actual test media.

Inadequate physical-chemical characterization of ENMs in nanotoxicology has a high cost, as described by Krug (2014) who warned that such deficiencies had reduced the significance of some studies to "total meaninglessness," and may lead to lack of confidence in ensuring safety of ENMs. Dissolution behavior can be heavily influenced by experimental factors such as sonication force and duration, medium composition, $\mathrm{pH}$, and temperature (Cohen et al. 2013; OECD 2012; Taurozzi et al. 2013). Solubility protocols which were not developed for ENMs (e.g., OECD 1995; OECD 2002) do not address nano-specific issues such as particle aggregation due to interaction with the surrounding medium (at the beginning of extractions) and separation of the dissolved fraction from solid NPs (at the end of extractions). Separation of the dissolved fraction presents a particular challenge for ENMs that are dissolved in complex biological media (e.g., cell culture media) due to the presence of various ligands (e.g., amino acids, proteins) that may bind the released metal and be retained on filters during separation (Avramescu et al. 2019; Bove et al. 2017; Koltermann-Jülly et al. 2018).

While it is understood that investigation of ENM toxicity must carefully consider solubility (Alkilany et al. 2016; Krug 2014; Misra et al. 2012a; Oberdörster and Kuhlbusch 2018), large data gaps remain due to the exponential increase in number and variety of ENMs. The term "read-across" refers to filling "potential data gaps in hazard characterization, based on availability of adequate data from similar substances" 
(ECHA 2016). That is, in the absence of information about a given ENM, its potential hazards may be characterized by using data from its bulk (macro-scale) analogue, or from another nanoform of the same substance (Arts et al. 2015a; ECHA 2016). Oberdörster and Kuhlbusch (2018) questioned the value of using water for evaluating solubility/dissolution behavior of ENMs for regulatory purposes, and instead recommended experiments that compare dissolution of the same metal compound under different physiologically relevant fluid compositions, as such comparative data are currently lacking. Another key parameter is the selection of experimental concentrations that are relevant to actual exposure levels (Hansen et al. 2017; Oberdörster and Kuhlbusch 2018). In order to support read-across, the dissolution behavior of the target ENM should be comparable with that of its bulk analogue (ECHA 2013), but this is not always the case, as shown by Semisch et al. (2014) for bulk and nano-CuO, which displayed large differences in solubility in cell culture media but not in distilled water or buffer. In general, experiments that have examined differences in dissolution between NPs and their bulk analogues have shown varying results, which depend on the NP and the surrounding medium (Misra et al. 2012a). Therefore, examining bulk-nano solubility relationships in relevant test media (versus water), and at relevant concentrations, is an urgent need for regulatory purposes (read across) and to inform the design of future nanotoxicology experiments.

The ultimate purpose of the present study was to address these risk assessment data gaps by comparing dissolution behavior of three metal oxide ENMs $\left(\mathrm{CuO}, \mathrm{NiO}\right.$, and $\left.\mathrm{TiO}_{2}\right)$ in water versus cell culture medium. Commercially available ENMs were selected because these are widely used in consumer products in Canada, and information is needed for their risk assessment. A key aspect of the experimental design focused on varying the initial ENM concentration to determine the extent to which this parameter affects solubility results. Initial concentrations of 10 and $100 \mathrm{mg} / \mathrm{L}$ were chosen because $10 \mathrm{mg} / \mathrm{L}$ is used commonly in toxicological assays (Decan et al. 2016), and OECD recommends $100 \mathrm{mg} / \mathrm{L}$ or higher for solubility testing (OECD TG 105 1995). Raw (uncoated) metal oxides were selected to permit evaluation of the influence of particle size on solubility, and to inform readacross efforts by comparing dissolution behavior of ENMs with that of their bulk analogues under the same sets of experimental conditions.

\section{Material and methods}

Materials and reagents

Table 1 summarizes the characteristics of metal oxide ENMs $\left(\mathrm{CuO}, \mathrm{NiO}\right.$, and $\left.\mathrm{TiO}_{2}\right)$ and their bulk analogues, obtained in dry powder form from Sigma-Aldrich (Oakville, ON, Canada), National Institute of Standards and Technology (Gaithersburg, Maryland, USA) and US Research Nanomaterials, Inc. (Houston, TX, USA). These ENMs were selected because they are currently in commerce in Canada. The identity of all metal oxide ENMs used in the present study (crystallographic structure and purity) were confirmed using powder X-ray diffraction as detailed elsewhere (Avramescu et al. 2019). Uncoated (raw) ENMs were required for the purpose of the present study, as evaluation of the influence of various surface coatings was beyond scope. A Mettler Toledo XP205 digital analytical balance equipped with a U-shaped static electrode was used to weigh samples. Appropriate personal protective equipment (face mask and gloves) was used during weighing and handling.

Cell culture medium (referred to as "DMEM" in this paper) used throughout the experiments was prepared as described in Decan et al. (2016) using Dulbecco's modified Eagle's medium Nutrient Mixture F-12HAM supplemented with $2 \%$ fetal bovine serum (FBS), $45 \mathrm{IU} / \mathrm{mL}$ penicillin, and $45 \mathrm{IU} / \mathrm{mL}$ streptomycin (Life Technologies Inc., Burlington, ON, Canada). The DMEM solution is rich in organic ligands and contains 21 amino acids, 10 vitamins, 12 inorganic salts, glucose, and other essential components to support cell culture. The complete composition of the DMEM/F-12 no phenol red (Life technologies, cat \# 21041) can be found on the supplier's website (https://www.thermofisher. com/ca/en/home/technical-resources/mediaformulation.57.html) and is included in Supplementary Material (Table S5). This medium is required for culturing lung epithelial cell lines (FE1 cells derived from MutaTMMouse) used for in vitro testing of chemicalinduced mutagenicity (Decan et al. 2016). Deionized water (MilliQ 18.2 M $\Omega \mathrm{cm}$ ) was used to prepare all metal oxide dispersions, all reagents, and calibration standards. Soluble $\mathrm{Cu}$ and Ni salts were purchased from Sigma-Aldrich and used to prepare solutions to evaluate recovery during dissolution experiments and separation. High-purity hydrochloric and nitric acids were obtained from SEASTAR Chemicals Inc. (Sidney, BC, Canada). 
Table 1 Characteristics of nano and bulk metal oxides as detailed in manufacturer/vendor's certificate of analysis or website

\begin{tabular}{|c|c|c|c|c|c|}
\hline Material & Details & CAS \# & $\begin{array}{l}\text { Average particle } \\
\text { size }(\mathrm{nm})\end{array}$ & $\begin{array}{l}\text { Specific surface area } \\
\left(\mathrm{SSA}, \mathrm{m}^{2} / \mathrm{g}\right)\end{array}$ & Purity \\
\hline Nano-CuO ${ }^{\mathrm{a}}$ & Nanopowder & $1317-38-0$ & 28 & 33 & $99.999 \%$ \\
\hline Nano-NiO ${ }^{b}$ & Nanopowder & $1313-99-1$ & $15-35$ & $50-100$ & $99.5+\%$ \\
\hline Nano- $\mathrm{TiO}_{2}{ }^{\mathrm{c}}$ & Nanopowder ( $76 \%$ anatase, $24 \%$ rutile) & $13463-67-7$ & $\begin{array}{l}19 \text { (Anatase) } \\
37 \text { (Rutile) }\end{array}$ & 55.55 & $99.4 \%$ \\
\hline Bulk $\mathrm{CuO}^{\mathrm{b}}$ & Bulk powder & $1317-38-0$ & 5000 & $4-6$ & $99.5 \%$ \\
\hline Bulk NiO ${ }^{b}$ & Bulk powder & $1313-99-1$ & 5000 & $5-20$ & $>99 \%$ \\
\hline Bulk $\mathrm{TiO}_{2}{ }^{\mathrm{b}}$ & Bulk powder $(76 \% \text { anatase, } 24 \% \text { rutile })^{\mathrm{d}}$ & $13,463-67-7$ & 1500 & $\sim 5-8$ & $99.9+\%$ \\
\hline
\end{tabular}

${ }^{\text {a }}$ Sigma-Aldrich (Oakville, ON, Canada)

${ }^{\mathrm{b}}$ US Research Nanomaterials, Inc. (Houston, TX, USA)

${ }^{\mathrm{c}}$ National Institute of Standards and Technology (Gaithersburg, MD, USA)

${ }^{\mathrm{d}}$ Anatase and rutile was mixed using the same proportion as in NIST SRM1898

Certified reference materials TM-24.4 and TMDA 64.3 (low- and high-level trace elements in water, respectively) were purchased from Environment Canada (Ottawa, $\mathrm{ON}$ ) for analytical quality assessment.

\section{ENM dispersion protocol}

Each metal oxide ENM dispersion was prepared using protocols optimized previously (Avramescu et al. 2019), following recommendations of Taurozzi et al. (2013) and Cohen et al. (2013). Previously, we showed that the sonication parameters must be optimized separately for each ENM, even for different lots of the same metal oxide ENM (Avramescu et al. 2019). As recommended by OECD (OECD 2017) to ensure proper interaction of the ENM surface with water during sonication, the required amount of dry ENM powder was pre-wetted in deionized water $(1 \mathrm{~mL})$ to form a wet paste and after $20 \mathrm{~h}$ was dispersed in deionized water to yield the required concentration. Stock dispersions of metal oxide ENMs $(1000 \mathrm{mg} / \mathrm{L}$ metal oxide) were prepared in deionized water (MilliQ 18.2 $\mathrm{M} \Omega$ ) and sonicated according to the materialspecific delivered sonication energy (DSE) using a Branson Ultrasonics SonifierTM SFX550 and a $1 / 2$ in horn probe with extension and removable flat tip (as described by Avramescu et al. (2019)). For dissolution experiments, freshly prepared stock ENM dispersions $(1000 \mathrm{mg} / \mathrm{L}$ and $100 \mathrm{mg} / \mathrm{L})$ were diluted 10 times (OECD 2017) either in deionized water or cell culture media.
Dynamic light scattering and electrophoretic light scattering

Particle size and zeta potential of each ENM dispersion (after sonication at material-specific DSE) were measured using a Zetasizer Nano ZSP particle characterization system (Malvern Panalytical, Westborough, MA, USA). The instrument is equipped with a $10 \mathrm{~mW}$ helium neon laser $(\lambda=633 \mathrm{~nm})$ and non-invasive backscatter (NIBS) technology detection ( $173^{\circ}$ scattering angle). The Zetasizer Nano ZSP uses dynamic light scattering to determine particle size, and laser Doppler electrophoresis in combination with M3-PALS to measure particle electrophoretic mobility from which zeta potential (ZP) is quantified. Measurement duration was set according to the manufacturer's recommendations. To measure zeta potential, the electrophoretic cell (DST1070) was washed with alcohol and rinsed thoroughly with deionized water as recommended by the manufacturer. Dynamic light scattering (DLS) is a fast non-invasive technique to directly measure the intensity-weighted size distribution (Malvern Instruments Ltd. 2019a, b) by monitoring the rate fluctuations in intensity of light scattered by particle suspended in liquid. The instrument software automatically determines the mean hydrodynamic diameter $\left(D_{h, \text { z-avg }}\right)$ and polydispersity index (PDI) by cumulants analysis (assumes monomodal size distribution and fits a single exponentially decaying function to the correlation data) and also analyzes the frequency distribution of particles (multiple exponential fit) (Malvern Instruments Ltd. 2019a, b). PDI is a measure of the broadness of size distribution within a given dispersion, and it is a dimensionless number with values 
from 0 (perfectly uniform sample) to 1 (highly polydisperse sample). Values greater than 0.7 may indicate that sample is too polydispersed for DLS measurement (Malvern Instruments Ltd. 2019a). The software reports summary statistics of mean $D_{h}$, PDI, peak diameters from distribution analysis, and zeta potential (surface charge). For each ENM sonication optimization, three independent dispersions were analyzed in triplicate with three measurements per triplicate subsample. For stock dispersion characterization and comparison with TRPS (described below), each stock dispersion was sampled in triplicate. For each of the triplicate samples, three DLS/ electrophoretic light scattering (ELS) measurements were performed and averaged.

Tunable resistive pulse sensing

The tunable resistive pulse sensing (TRPS) size distribution was obtained with a qNano Gold instrument (Izon Science Ltd., Christchurch, New Zealand) using precisely size-controlled (tunable) nanopore membranes (NP) in the range of interest (NP300). TRPS system is based on the conventional Coulter counter and measures the reduction in current that results as each particle (or agglomerate) passes through a membrane containing a single tunable (nano)pore (Anderson et al. 2013; Pal et al. 2014). The technique provides information about the particle size (based on extent of current reduction) on a particle-by-particle basis and also particle concentration (frequency of the pulses; \#/mL) (Anderson et al. 2013; IZON Scientific 2019; Pal et al. 2014) which allows calculation of the fraction represented by each peak (Supplemental Information, Table S1). It should be noted that the TRPS technique requires the particles to be suspended in a conductive electrolyte (i.e., PBS or other physiological media), and that different sizes of nanopores require the electrolyte solution to fall within specific conductivity ranges. That is, for samples containing larger particle sizes that require larger nanopores, a more diluted electrolyte is required which may introduce an artifact by promoting unwanted changes in particle size (e.g., by agglomeration or dissolution). For TRPS measurement, the optimized ENM stock dispersions in water were diluted to $20 \mathrm{mg} / \mathrm{L}$ in DMEM (or PBS in case of $\mathrm{TiO}_{2}$ ) and analyzed in triplicate following a protocol adapted from $\mathrm{Pal}$ et al. (2014) combined with the manufacturer's instructions. For comparison, the same dispersion concentration (20 $\mathrm{mg} / \mathrm{L})$ was used for DLS measurements. A maximum of 500 counts was established as the upper limit, because longer runs (1000 counts) resulted in frequent blockages of the nanopores, making measurements very difficult or impossible to complete. The samples were measured at two pressures (high $=\mathrm{P} 1$, low $=$ P2) where possible. For certain sample replicates where frequent blockages of the nanopore occurred at the lower pressure (P2), only the results from the highest pressure (P1) were reported. Instrument calibration was performed using IZON calibration particles of different diameters (CPC $100 \mathrm{~nm}, 200 \mathrm{~nm})$. Sample replicates were also measured by DLS for comparison.

\section{Dissolution experiments}

Dissolution experiments were conducted in water and cell culture medium (DMEM) following a batch protocol adapted from OCED TG 105 (OECD 1995). Stock dispersions of each metal oxide ENM prepared by sonication (as described earlier) were diluted to required initial concentration, 10 or $100 \mathrm{mg} / \mathrm{L}$, in each medium. Samples $(50 \mathrm{~mL})$ were incubated in $50-\mathrm{mL}$ polypropylene centrifuge tubes at $37^{\circ} \mathrm{C}$ for $24 \mathrm{~h}$ (and $48 \mathrm{~h}$ in some cases; Table S2) in an orbital shaker (MaxQ4000, Thermo Scientific, Canada) with 1-h shaking per day (OECD 1995) at $100 \mathrm{rpm}$ (Semisch et al. 2014). At each time interval, triplicate samples were withdrawn and aliquots were taken for particle characterization (before separation) while the remaining dispersions were used to measure the solubilized metal fraction after separation from undissolved particles. The separation was performed by sequential centrifugation at $20,000 \times g(2 \times 30 \mathrm{~min}$ for $\mathrm{Cu}, 3 \times 30 \mathrm{~min}$ for $\mathrm{Ti}$ and $\mathrm{Ni}$ ) using an Allegra 64R centrifuge (Beckman Coulter, Canada) as previously optimized (Avramescu et al. 2019). Between successive centrifugation steps, the samples were carefully transferred by pipette $(30 \mathrm{~mL}$ first step, $15 / 20 \mathrm{~mL}$ second step) from the top part of supernatant to avoid particle re-suspension. The absence of particles from the resulting supernatant was confirmed by DLS (Avramescu et al. 2019; Semisch et al. 2014; Sohal et al. 2018). All final extracts were acidified with $\mathrm{HNO}_{3}$ (to a concentration of $2.5 \%$ ), and dissolved metal concentration was determined using inductively coupled plasma-optical emission spectrometry (ICPOES). Procedural blanks and spiked matrix blanks $(0.5 \mathrm{ppb}-1 \mathrm{ppm} \mathrm{Cu}, \mathrm{Ni}$, or $\mathrm{Ti})$ were incubated along with the samples. The $\mathrm{pH}$ of the extracts was monitored at each incubation time using a Seven Compact S220 
$\mathrm{pH}$ meter (Mettler Toledo) calibrated daily ( $\mathrm{pH} \mathrm{4,} \mathrm{7,} 10$ buffer solutions), and the results presented in Table S2 (Supplementary Material). The cell culture medium (DMEM) is buffered at $\mathrm{pH}$ range $7.4-7.8$ which is maintained after the addition of $2 \%$ FBS. Solubility was calculated both as $\mathrm{mg} / \mathrm{L}$ metal dissolved and percent of total metal dissolved.

The dissolved metal concentrations were determined using a 5100 Synchronous Vertical Dual View (SVDV) ICP-OES (Agilent Technologies, Canada) at wavelengths recommended by the manufacturer $(\mathrm{Cu}$ $327.395 \mathrm{~nm}$, Ti 334.941, Ni $231.604 \mathrm{~nm}$ ). The instrument was operated at a $1.2 \mathrm{~kW}$ power, and $12 \mathrm{~L} / \mathrm{min}$ plasma, $1 \mathrm{~L} /$ min auxiliary, and $0.7 \mathrm{~L} / \mathrm{min}$ nebulizer flow rates, in SVDV viewing mode. Daily optimization was conducted using ICP-OES wavelength calibration solution containing $5 \mathrm{mg} / \mathrm{L} \mathrm{Al}, \mathrm{As}, \mathrm{Ba}, \mathrm{Cd}, \mathrm{Co}, \mathrm{Cr}, \mathrm{Cu}, \mathrm{Mn}$, $\mathrm{Mo}, \mathrm{Ni}, \mathrm{Pb}, \mathrm{Se}, \mathrm{Sr}$, and $\mathrm{Zn}$ and $50 \mathrm{mg} / \mathrm{L} \mathrm{K}$ in $5 \% \mathrm{HNO}$. Three replicate readings were taken for all monitored wavelengths and elements. External calibration was conducted using matrix-matched standards prepared from $1000 \mu \mathrm{g} / \mathrm{mL} \mathrm{Cu}, \mathrm{Ni}$, and Ti high-purity standard solutions (Delta Scientific Ltd., Mississauga, ON, Canada). Detection limits (calculated as three times the standard deviation of the procedural blanks) were $0.00023 \mathrm{mg} / \mathrm{L}$ for $\mathrm{Cu}, 0.00094 \mathrm{mg} / \mathrm{L}$ for $\mathrm{Ni}$ and $0.00018 \mathrm{mg} / \mathrm{L}$ for $\mathrm{Ti}$ (in water) and $0.00220 \mathrm{mg} / \mathrm{L}$ for $\mathrm{Cu}, 0.00102 \mathrm{mg} / \mathrm{L}$ for $\mathrm{Ni}$, and $0.00017 \mathrm{mg} / \mathrm{L}$ for $\mathrm{Ti}$ (in DMEM). The recovery range for TM 24.4 and TMDA 64.3 trace element reference materials was $80-105 \%$ for all three elements. Samples were matrix blank corrected. Spiked media recoveries were in the range of 93.4 $104.2 \%$ for water and 88.6-109.7\%, for DMEM.

\section{Results and discussion}

Characterization of stock nanoparticle dispersion with DLS and TRPS techniques

Two instrumental approaches were used to characterize stock dispersions in the present study: DLS which provides an intensity-weighted particle size distribution (Malvern Instruments Ltd. 2019b) and TRPS which counts each particle individually to provide the particle size distribution (Anderson et al. 2013; IZON Scientific 2019; Pal et al. 2014). As summarized in Table 2, both techniques provided complementary results, with all three metal oxide ENM dispersions displaying mean diameters in the 157-207-nm range. These results represented the smallest attainable particle size, which was the goal of optimizing the sonication protocol separately for each metal oxide ENM. It is typical for metal oxide ENMs to rapidly form agglomerates when suspended in aqueous medium which are several times larger than the primary particle size of the dry nanopowder (Cohen et al. 2013; Jiang et al. 2009; OECD 2012; Taurozzi et al. 2011). The use of two different measurement technologies in the present study complied with OECD guidance (OECD 2012) to use at least two complementary techniques for characterization of particle size distribution of ENMs, a recommendation that is too often ignored according to Hansen (2017).

Figure 1 illustrates that all three metal oxide ENMs were relatively monodispersed in the submicron range, using both instrumental approaches. When characterized using DLS (Fig. 1a, c, and e), all three ENM dispersions showed the presence of a single peak in the submicron range, consistent with the monomodal distributions characterized using TRPS (Fig. 1b, d, and f). The TRPS displayed a wider spread for the $\mathrm{NiO}$ distribution (Fig. 1d) compared with that of $\mathrm{CuO}$ and $\mathrm{TiO}_{2}$ (Fig. 1b, f, respectively). This observation was consistent with the higher polydispersity index (PDI) value for the $\mathrm{NiO}$ dispersion reported using DLS $(\mathrm{PDI}=0.3$; Table 2) compared with that of $\mathrm{CuO}$ and $\mathrm{TiO}_{2}(\mathrm{PDI}<0.15$; Table 2$)$. The greater polydispersity of the $\mathrm{NiO}$ dispersion reflected greater heterogeneity in the agglomeration of $\mathrm{NiO}$ NPs compared with $\mathrm{CuO}$ and $\mathrm{TiO}_{2}$. The same dispersions were tested again after $24 \mathrm{~h}$ and yielded similar particle size distributions (not shown), indicating that the dispersions remained stable. These results confirmed the effectiveness of optimizing the sonication protocol separately for each ENM to "achieve a suspension with the smallest possible agglomerates that are minimally polydispersed and maximally stable over time" (Cohen et al. 2013; Deloid et al. 2017).

There were some differences in the type of information provided by DLS and TRPS (Table 2), and both techniques provided additional information not included in Table 2 (summarized in Supplementary Material Table S1). An advantage of TRPS was its capacity to provide information about the particle number concentration (particles $/ \mathrm{mL}$ ) in the three dispersions (Table 2). The number-based size distribution provided by TRPS may be better suited to characterize dispersions that are polymodal (Anderson et al. 2013; Pal et al. 2014). 
Table 2 Characterization of $\mathrm{CuO}, \mathrm{NiO}$, and $\mathrm{TiO}_{2}$ ENM dispersions in biological media $(20 \mathrm{mg} / \mathrm{L})$ using dynamic light scattering (DLS) and tunable resistive pulse sensing (TRPS). Results are presented as the mean and standard deviation (SD) of three replicates (except for nano-NiO dispersion: two replicates). Table S1 (Support Information) contains additional information provided by both methods

\begin{tabular}{|c|c|c|c|c|c|c|}
\hline \multirow[t]{2}{*}{ ENM } & \multicolumn{2}{|l|}{ DLS } & \multicolumn{3}{|l|}{ TRPS } & \multirow[t]{2}{*}{ Dispersant } \\
\hline & mean $\mathrm{D}_{\mathrm{z} \text {-ave }}(\mathrm{SD}), \mathrm{nm}$ & PDI (SD) & mean D (SD), nm & mode $\mathrm{D}(\mathrm{SD}), \mathrm{nm}$ & concentration (SD), $\# / \mathrm{mL}$ & \\
\hline Nano-CuO & $192(4.8)$ & $0.12(0.05)$ & $185(0.6)$ & $165(9.7)$ & $1.88(0.10) \mathrm{E}+10$ & DMEM \\
\hline Nano-NiO & $157(7.2)$ & $0.32(0.001)$ & $207(21.2)$ & $186(9.9)$ & $3.73(0.37) \mathrm{E}+10$ & DMEM \\
\hline Nano- $\mathrm{TiO}_{2}$ & $169(0.4)$ & $0.14(0.02)$ & $159(18.8)$ & $131(8.7)$ & $1.64(0.86) \mathrm{E}+12$ & PBS \\
\hline
\end{tabular}

$D L S \mathrm{D}_{\mathrm{z}-\text { ave }}$ hydrodynamic diameter; $P D I$ polydispersity index (measure of the broadness of size distribution); TRPS no filter applied (overall); for additional details see Table S1 (Supplementary Material)

However, TRPS had some limitations: it was difficult to characterize particles below $40 \mathrm{~nm}$ and problems with frequent blockage of the nanopore membrane made this technique very labor-intensive. Another limiting factor of TRPS was the requirement for very dilute suspensions in a conductive electrolyte (PBS is the default electrolyte for TRPS). Consequently, ENM stock dispersions made with water had to be further diluted in electrolyte for TRPS characterization. Considering these limitations, and since the results from Table 2 show consistency between DLS and TRPS, only the DLS technique was selected for testing particle size distribution after dilution of the stock dispersion in the media at varying times during the solubility experiments (summarized in Supplementary Material Tables S3 A and B).

Comparison of dissolution behavior in cell culture medium versus water

\section{Effect of particle size on dissolution of metal oxides}

The influence of particle size was evaluated by comparing dissolution behavior of ENMs with that of their bulk (macro-scale) analogues. Table 3 shows the influence of particle size on percent solubility of nano and bulk $\mathrm{CuO}$, $\mathrm{NiO}$, and $\mathrm{TiO}_{2}$ after 24-h incubation in water and cell culture medium at an initial metal oxide concentration of $100 \mathrm{mg} / \mathrm{L}$. Results showed that all three metal oxide ENMs were more soluble than their bulk analogues in both investigated media (Table 3). In water, the greatest difference between nano and bulk metal oxide solubility was observed for nano- $\mathrm{TiO}_{2}(42 \times$ higher than bulk), followed by nano-NiO $(25 \times$ higher $)$ and nano-CuO (6× higher). In cell culture medium, the difference in solubility between nano and bulk was even greater for nano- $\mathrm{TiO}_{2}(90 \times$ higher than bulk) and for nano-CuO $(38 \times$ higher), while the trend for nano-NiO was similar to that in water, about $22 \times$ higher than its bulk analogue. Table S2 (Supplementary Material) shows that after $48 \mathrm{~h}$, similar results were observed in cell culture medium for nano- $\mathrm{CuO}(34 \times$ higher than bulk $)$ and nano-NiO $(27 \times$ higher $)$ and in water for nano-NiO $(23 \times$ higher $)$.

Overall, the three bulk metal oxides showed very low solubility after $24 \mathrm{~h}$ in both water $(<0.2 \%)$ and cell culture medium $(<1.2 \%)$, which decreased in the order $\mathrm{CuO}>\mathrm{NiO}>\mathrm{TiO}_{2}$ (Table 3). While the difference in aqueous medium had a minor effect on the solubility of bulk $\mathrm{NiO}$ and bulk $\mathrm{TiO}_{2}$ (Table 3), bulk $\mathrm{CuO}$ was about $6 \times$ more soluble in cell culture medium $(1.17 \%)$ than in water $(0.17 \%)$. In the case of nano-CuO, the effect of aqueous medium was greatly magnified: $44.5 \%$ in DMEM compared with $0.99 \%$ in water. The enhancement of $\mathrm{Cu}$ oxide dissolution in cell culture medium (compared with water) is likely due to the formation of $\mathrm{Cu}$-ion complexes caused by the presence of amino acids and proteins (Hedberg et al. 2016; Semisch et al. 2014). The dissolution time of $48 \mathrm{~h}$ was used to match the timescale of the toxicity tests with FE1 cells. Overall, in this study, the solubility maximum of the metal oxide in water was not reached because the study was terminated after $48 \mathrm{~h}$. Future work may include longer studies required for equilibrium to be reached. Results of $t$ tests (Table S4) confirmed that for all three metal oxides, solubility was significantly higher than that of their bulk analogues in both water $(p<0.001)$ and DMEM $(p=0.002 \mathrm{CuO}, p<0.001 \mathrm{NiO}, p<0.016$ $\mathrm{TiO}_{2}$ ).

Several previous studies have reported higher solubility of metal oxide ENMs compared with their bulk 


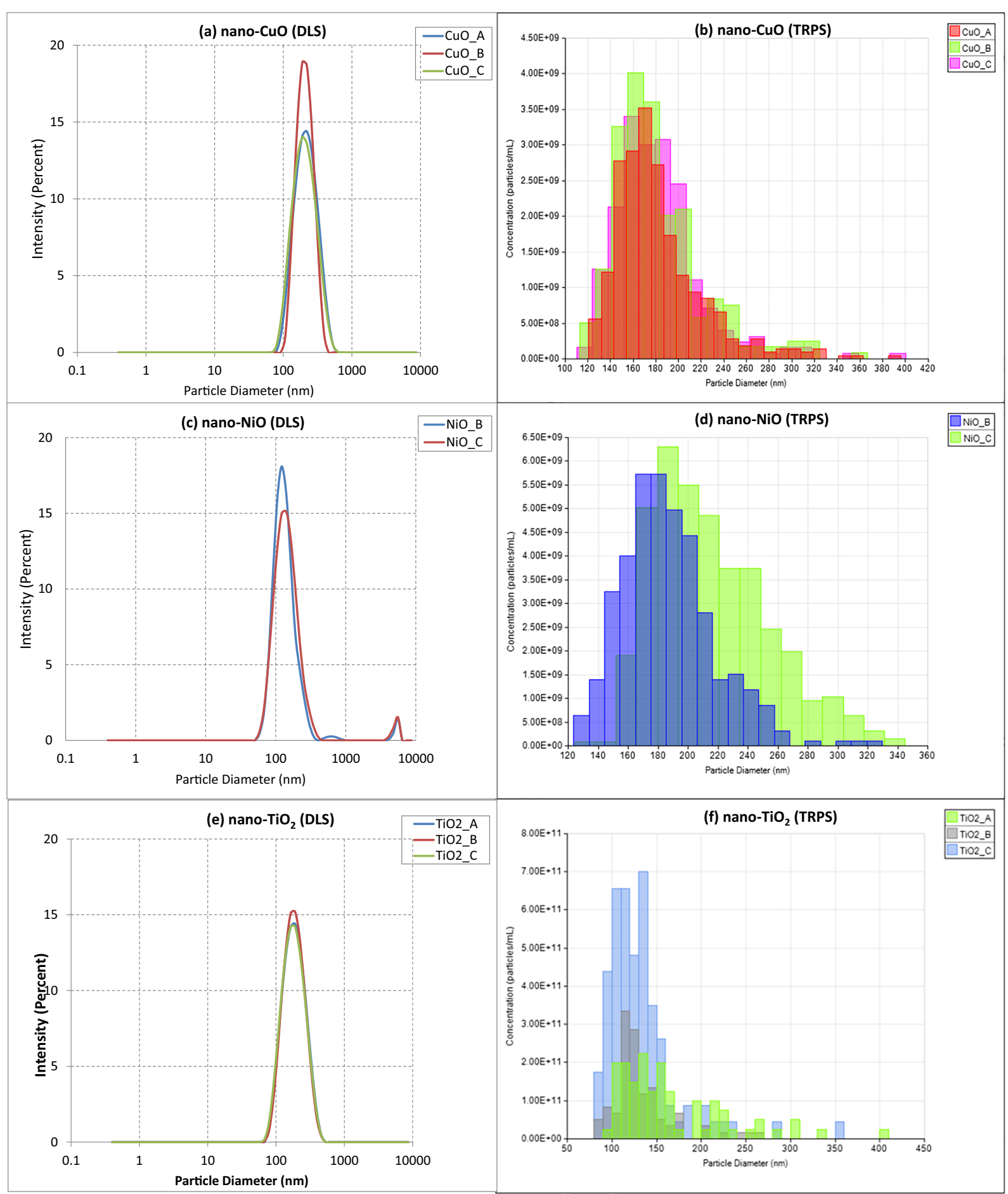

Fig. $1 \mathrm{CuO}, \mathrm{NiO}$, and $\mathrm{TiO}_{2}$ ENM particle size distribution measured using dynamic light scattering (DLS-a, c, e) and tunable resistive pulse sensing (TRPS - b, d, f)

analogues (Latvala et al. 2016; Midander et al. 2009; Semisch et al. 2014; Studer et al. 2010). Semisch et al. (2014) compared dissolution of nano- and micro-scale
$\mathrm{CuO}$ particles for $24 \mathrm{~h}$ at $37^{\circ} \mathrm{C}$ in water and cell culture medium (DMEM/FCS) after separation by repeated centrifugation at $16,000 \times \mathrm{g}$ of collected supernatants. 
Table 3 Influence of particle size (nano versus bulk) on $\%$ solubility of $\mathrm{CuO}, \mathrm{NiO}$, and $\mathrm{TiO}_{2}$ after 24-h incubation in water and DMEM. Initial metal oxide concentration was $100 \mathrm{mg} / \mathrm{L}$.
Results presented as mean (standard deviation) of triplicates. Table S2 shows additional characterization information, and Table S4 shows significance using $t$ tests

\begin{tabular}{|c|c|c|c|c|c|c|}
\hline \multirow[t]{2}{*}{ Material } & \multirow[t]{2}{*}{ Media } & \multicolumn{2}{|l|}{$\%$ Dissolved } & \multirow{2}{*}{$\begin{array}{l}\text { Ratio } \\
\text { Nano/bulk }\end{array}$} & \multicolumn{2}{|l|}{$\mathrm{pH}$} \\
\hline & & Nano & Bulk & & Nano & Bulk \\
\hline \multirow[t]{2}{*}{$\mathrm{CuO}$} & Water & $0.99(0.04) \%$ & $0.17(0.02) \%$ & 6 & $6.54(0.05)$ & $6.13(0.16)$ \\
\hline & DMEM & $44.5(1.33) \%$ & $1.17(0.09) \%$ & 38 & $7.83(0.03)$ & $7.68(0.07)$ \\
\hline \multirow[t]{2}{*}{$\mathrm{NiO}$} & Water & $1.09(0.01) \%$ & $0.043(0.001) \%$ & 25 & $7.32(0.14)$ & $7.37(0.08)$ \\
\hline & DMEM & $1.16(0.08) \%$ & $0.052(0.003) \%$ & 22 & $7.76(0.03)$ & $7.73(0.02)$ \\
\hline \multirow[t]{2}{*}{$\mathrm{TiO}_{2}$} & Water & $0.008(0.001) \%$ & $0.0002(0.00001) \%$ & 42 & $6.69(0.25$ & $6.26(0.07)$ \\
\hline & DMEM & $0.045(0.012) \%$ & $0.0005(0.0003) \%$ & 90 & $7.77(0.02)$ & $7.73(0.05)$ \\
\hline
\end{tabular}

The authors found that, regardless of the media, more $\mathrm{Cu}$ was released from nano- $\mathrm{CuO}$ than from bulk $\mathrm{CuO}$, and dissolution was highly accelerated for both forms in DMEM/FCS (44\% nano; $4 \%$ bulk) than in water ( $2 \%$ nano; $<1 \%$ bulk). Latvala et al. (2016) also observed greater solubility of nano- $\mathrm{NiO}$ compared with bulk $\mathrm{NiO}$ in various media (i.e., cell media, PBS, ALF) at $10 \mu \mathrm{g} /$ $\mathrm{mL}$ initial concentration. Even though the solubility was marginal (1-3\%) in cell culture medium (DMEM $+10 \%$ FBS) for both $\mathrm{NiO}$ forms, nano-NiO was more soluble than bulk $\mathrm{NiO}(\sim 16 \mu \mathrm{g} / \mathrm{mL}$ and $<1 \mu \mathrm{g} / \mathrm{mL}$, respectively). Those findings are consistent with findings for the ENMs investigated in the present study.

It is known that the solubility of $\mathrm{CuO}$ is dependent on pH (Wang et al. 2013; Leitner et al. 2019) and on complexing species such as $\mathrm{Cl}^{-}, \mathrm{CO}_{3}{ }^{2-}$, or $\mathrm{PO}_{4}{ }^{3-}$ that may be present in the medium (Wang et al. 2013; Leitner et al. 2019; Adeleye et al. 2014). Odzak et al. (2014) observed total dissolution of nano- $\mathrm{CuO}$ in simulated natural water (containing $\mathrm{Ca}^{2+}, \mathrm{Mg}^{2+}, \mathrm{Na}^{+}, \mathrm{K}^{+}$, $\mathrm{NH}_{4}{ }^{+}, \mathrm{NO} 3-, \mathrm{SO}_{4}{ }^{2-}, \mathrm{HCO}_{3}{ }^{-}, \mathrm{PO}_{4}{ }^{3-}$, and MOPS buffer, $\mathrm{pH}=6.1)$ while Misra et al. (2012b) observed only $1-$ $3.5 \%$ dissolution of $\mathrm{CuO}$ in a simple medium $(1 \mathrm{mM}$ $\mathrm{NaNO}_{3}$ solution, $\mathrm{pH}$ 6.7), but at a higher concentration. Anions present in the media may increase $\mathrm{CuO} N \mathrm{NP}$ dissolution by shifting the ion-particle equilibrium (Leitner et al. 2019; Misra et al. 2012b; Wang et al. 2013). In particular, chloride ions, which are abundant in cell culture medium, may increase $\mathrm{CuO}$ dissolution. Adeleye et al. (2014) showed that $\mathrm{CuO}$ dissolution increased to $2.42 \%$ due to the increase in ionic strength caused by increasing $\mathrm{NaCl}$ concentration from 1 to $100 \mathrm{mM}$ in the presence of extracellular polymeric substances (EPS). In contrast, Gunawan et al. (2011) found that the presence of $\mathrm{NaCl}$ had no effect on $\mathrm{CuO}$ solubility (regardless of particle size), and observed instead that the presence of tryptone and yeast extract in an amino-rich medium led to almost complete dissolution of $\mathrm{CuO}$ NPs (80-95\% dissolved) but significantly lower dissolution of micron-sized $\mathrm{CuO}(1-2 \%$ dissolved).

Consequently, as part of physical-chemical characterization of ENMs, the evaluation of solubility is important not only in water but also in biologically relevant fluids, for understanding ENM behavior and interactions in different compartments of the body. Regardless of particle size, the water solubility of all investigated metal oxides was low to negligible $(<1 \%)$. In contrast, solubility of all the ENMs was enhanced in DMEM compared with their solubility in water and also compared with the solubility of their bulk analogues in DMEM. For example, the solubility of nano-CuO in DMEM was $45 \times$ higher than its solubility in water and $6 \times$ higher than the solubility of bulk $\mathrm{CuO}$ in DMEM $(1.17 \%)$. This result shows that in the context of read across, bulk $\mathrm{CuO}$ would not be a good model for nano$\mathrm{CuO}$ due to their pronounced differences in solubility in cell culture medium.

\section{Effect of initial metal oxide ENM concentration on dissolution}

The effect of varying the initial ENM concentration was evaluated for the three metal oxide ENMs in both water and cell culture media (Fig. 2). Solubility at the "low initial concentration" was evaluated using $10 \mathrm{mg} / \mathrm{L}$, and the "high initial concentration" was 
evaluated using $100 \mathrm{mg} / \mathrm{L}$ for $\mathrm{CuO}, \mathrm{NiO}$, and $\mathrm{TiO}_{2}$ ENMs in both media (Fig. 2).

$\mathrm{CuO}$ and $\mathrm{NiO}$ ENMs showed similar trends (Fig. $2 \mathrm{a}, \mathrm{b}$ ) in water (where both ENMs showed greater solubility at the low concentration) and in DMEM (where both showed lower solubility at the low concentration). Figure 2a shows greater solubility of nano- $\mathrm{CuO}$ in water at low compared with high initial concentration (3.31\% at $10 \mathrm{mg} / \mathrm{L}$ compared with $0.99 \%$ at $100 \mathrm{mg} / \mathrm{L}$ ). In contrast, in DMEM, this trend was reversed with much greater solubility of nano- $\mathrm{CuO}$ at the high initial concentration $(44.5 \%$ at $100 \mathrm{mg} / \mathrm{L}$ compared with $11.8 \%$ at $10 \mathrm{mg} / \mathrm{L}$, Fig. 2a). Nano-NiO responded similarly to the change in media (i.e., reversal in the effect of initial concentration), but the magnitude of dissolution was lower for nano-NiO in both media (note $y$-axis in Fig. 2b). This was also supported by $t$ test results (Table S4) that showed significantly higher solubility for nano- $\mathrm{CuO}$ and nano-NiO at low initial concentration $(p<0.001)$ in water but significantly higher solubility at high initial concentration in water. Overall, significantly increased dissolution was observed in DMEM compared with water for nano- $\mathrm{CuO}$ at both concentrations $(p<0.001)$, while for nano-NiO, the effect of aqueous medium was significant only at low initial concentration $(p<0.001)$. Interestingly, the $\mathrm{TiO}_{2} \mathrm{ENM}$ showed the opposite dissolution trend compared with that of $\mathrm{CuO}$ and $\mathrm{NiO}$ ENMs. Figure 2c shows that, in water, solubility of nano- $\mathrm{TiO}_{2}$ was measurable only at the high initial concentration, whereas its solubility at low initial concentration was below the limit of detection. In DMEM, in contrast, nano- $\mathrm{TiO}_{2}$ solubility was significantly higher $(p=0.009$, Table S4) at the lower initial concentration $(0.17 \%$ for $10 \mathrm{mg} / \mathrm{L}$ versus $0.045 \%$ for $100 \mathrm{mg} / \mathrm{L}$; Fig. 2c).

Table 4 summarizes the dissolution data as percent solubility and concentration $(\mathrm{mg} / \mathrm{L})$ for all three investigated metal oxide ENMs. In water, the solubility of all three ENMs was relatively low ( $\leq 3.31 \%$; Table 4$)$, but the initial concentration did have varying effects on solubility. Water solubility at low initial concentration was 2.5 times higher for nano- $\mathrm{CuO}$ than nano-NiO, whereas at high concentration, their solubilities were similar in magnitude (Table 4). In DMEM, however, nano- $\mathrm{CuO}$ displayed elevated solubility compared with nano-NiO regardless of the initial concentration. Overall, in both media, the dissolution decreased from $\mathrm{CuO} \geq$ $\mathrm{NiO}>\mathrm{TiO}_{2}$ (Table 4). In the context of grouping ENMs according to solubility, nano- $\mathrm{TiO}_{2}$ dissolution at either
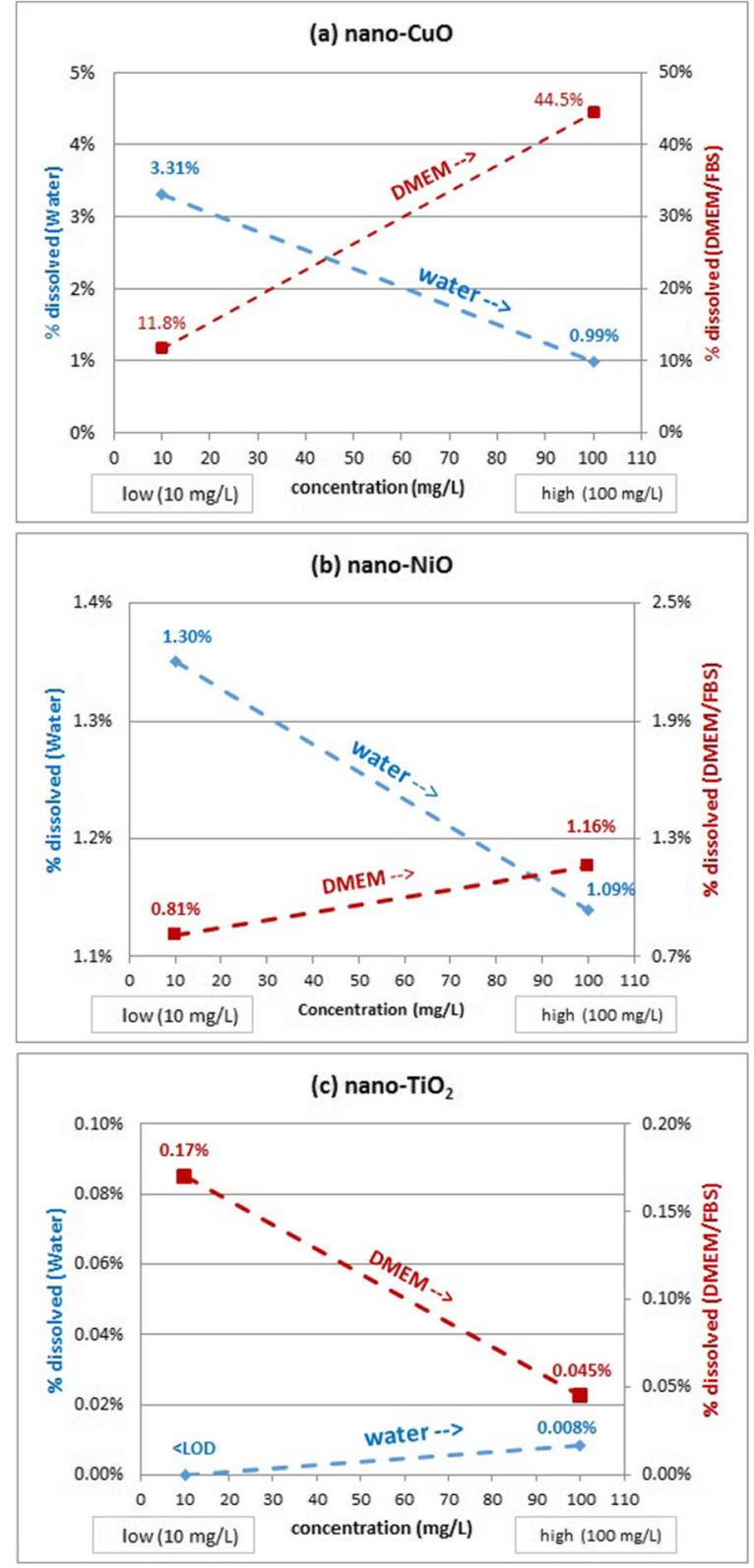

Fig. 2 Influence of aqueous medium on \% solubility of $\mathrm{CuO}$, $\mathrm{NiO}$, and $\mathrm{TiO}_{2}$ ENMs at different initial concentrations $(10 \mathrm{mg} / \mathrm{L}$ versus $100 \mathrm{mg} / \mathrm{L}$ ). < LOD below limit of detection. Dash lines (blue water; red DMEM) are used only to show solubility trend in a given medium not linear relationship

initial concentration may be considered negligible (defined as $<1 \%$ by OECD guideline 44 (2015) in both media, even though its solubility was slightly enhanced in DMEM compared with water (Fig. 2c).

The flip in zeta potential (surface charge) from positive in water to negative in DMEM shown in Table S3 
Table 4 Influence of initial concentration $(10 \mathrm{mg} / \mathrm{L}$ versus $100 \mathrm{mg} / \mathrm{L}$ ) on solubility of $\mathrm{CuO}, \mathrm{NiO}$, and $\mathrm{TiO}_{2}$ ENMs in water and DMEM after 24-h incubation. The results are presented as the mean (standard deviation) of three replicates and expressed as percent solubility and as concentration $(\mathrm{mg} / \mathrm{L})$. Table $\mathrm{S} 2$ contains additional results for additional incubation times, and Table S4 shows significance using $t$ tests

\begin{tabular}{|c|c|c|c|c|c|}
\hline \multirow[t]{2}{*}{ ENM } & \multirow[t]{2}{*}{ ENM's initial concentration } & \multicolumn{2}{|l|}{ Water } & \multicolumn{2}{|l|}{ DMEM } \\
\hline & & Dissolved (mg/L) & Dissolved (\%) & Dissolved (mg/L) & Dissolved (\%) \\
\hline \multirow[t]{2}{*}{ Nano-CuO } & $10 \mathrm{mg} / \mathrm{L}$ & $0.31(0.01)$ & $3.31(0.09) \%$ & $0.94(0.01)$ & $11.8(0.15) \%$ \\
\hline & $100 \mathrm{mg} / \mathrm{L}$ & $0.79(0.03)$ & $0.99(0.04) \%$ & $35.6(1.12)$ & $44.5(1.33) \%$ \\
\hline \multirow[t]{2}{*}{ Nano-NiO } & $10 \mathrm{mg} / \mathrm{L}$ & $0.10(0.001)$ & $1.30(0.02) \%$ & $0.07(0.001)$ & $0.81(0.01) \%$ \\
\hline & $100 \mathrm{mg} / \mathrm{L}$ & $0.86(0.004)$ & $1.09(0.01) \%$ & $0.91(0.06)$ & $1.16(0.08) \%$ \\
\hline \multirow[t]{2}{*}{$\mathrm{Nano}^{-\mathrm{TiO}_{2}}$} & $10 \mathrm{mg} / \mathrm{L}$ & $<\mathrm{LOD}$ & $<\mathrm{LOD}$ & $0.013(0.0034)$ & $0.170(0.044) \%$ \\
\hline & $100 \mathrm{mg} / \mathrm{L}$ & $0.0052(0.0008)$ & $0.0083(0.0013) \%$ & $0.027(0.0072)$ & $0.045(0.012) \%$ \\
\hline
\end{tabular}

$<L O D$ below limit of detection

demonstrates the dramatic difference in physicalchemical properties of NPs dispersed in cell culture medium (to which cells are exposed in a toxicity assay), compared with water. This flip in surface charge may be attributed to the formation of a negatively charged protein corona (Alkilany et al. 2016), meaning that cells bathed in a DMEM dispersion would be exposed to anionic NPs (due to protein adsorption) rather than to their original cationic form. These observed changes in the effective surface charge of NPs upon exposure to biological media support the recommendation by Oberdörster and Kuhlbusch (2018) to use physiologically relevant media to assess solubility for categorization purposes.

The complexity of the influence of various medium components on metal oxide NP solubility has been noted by other authors who concluded that ionic strength, type of electrolyte, and the presence of organic ligands all affect solubility (Midander et al. 2009; Oberdörster and Kuhlbusch 2018; Peng et al. 2017). Efforts to predict NP dissolution processes in complex media using equilibrium models such as MINTEQ (summarized in Supplementary Material) have been hampered by lack of information for most of the ligands present in cell culture media (amino acids, vitamins, etc.). Additionally, in the presence of cells, organic materials will be exuded into the media, and those biomacromolecules may increase or decrease NP dissolution depending on the NP surface characteristics and interactions with other media components that affect NP surface activity (Adeleye et al. 2014; Yamada et al. 1993). This issue is further discussed in Supplemental Material. Even the addition of FBS to the cell culture medium, as in the present study, affects dissolution of metal oxide NPs: for example, dissolution of nano-NiO was virtually undetectable in Minimal Essential Medium (MEM) without FBS, but increased to $21.8 \%$ in the presence of FBS (Minigalieva et al. 2017). Karlsson et al.(2014) measured the metal released from various metal oxide NPs incubated for $24 \mathrm{~h}$ in cell culture medium (DMEM+10\% FBS), and observed the same overall solubility trend, increasing from nano- $\mathrm{TiO}_{2}$ $(0.1 \%)$ to nano-NiO $(5.1 \%)$ to nano-CuO (37. $2 \%)$. Käkinen et al. (2016) studied the dissolution of two types of nano- $\mathrm{CuO}$ in water and cell culture medium (MEM supplemented with 15\% FBS) and also observed increased dissolution in the cell culture medium (i.e., $40.1 \%$ MEM) compared with water $(0.9 \%)$ after $24 \mathrm{~h}$ incubation. Karlsson et al. (2013) incubated nano- $\mathrm{CuO}$ $(100 \mathrm{mg} / \mathrm{L})$ in cell culture media (DMEM+10\% FCS) and observed $29 \% \mathrm{Cu}$ released after $4 \mathrm{~h}$. Hansjosten et al. (2018) studied solubility of $\mathrm{TiO}_{2}$ ENMs in water $(\mathrm{pH} 7)$ and found that the percent dissolved varied from $0 \%\left(\mathrm{TiO}_{2}\right.$-plain) to $0.233 \%\left(\mathrm{TiO}_{2} \mathrm{NM}-104\right)$. Wohlleben et al. (2013) investigated dissolution of $\mathrm{TiO}_{2} \mathrm{NM} 105$ $(10 \mathrm{mg} / \mathrm{mL})$ in water and simulated biological media at $25^{\circ} \mathrm{C}$ and found that released $\mathrm{Ti}$ increased from below detection limit in water to $0.15 \mathrm{wt} \%$ in biological media (PSF). Considering various $\mathrm{TiO}_{2}$ ENMs, very minor solubility $(\sim 1 \mathrm{wt} \%)$ was also observed in different simulated biological media by Jensen et al. (2013) and the authors concluded that $\mathrm{TiO}_{2}$ is almost insoluble in the media investigated. These results are consistent with the results of the present study.

Zhang et al. (2012) investigated the potential toxicity of various metal oxide ENMs (including $\mathrm{CuO}, \mathrm{NiO}$, 
$\mathrm{TiO}_{2}$ ) based on correlation between the percent metal dissolved (water and cell culture media) and their conduction band gap energy (Ec, eV) values. Based on solubility in water and cell culture media, Zhang et al. (2012) classified the ENMs as "dissolvable" (>13.05\% dissolved, i.e., $\mathrm{CuO}$ and $\mathrm{ZnO}$ ENMs) and "less dissolvable" ( $<13.05 \%$ dissolved; e.g., $\mathrm{Mn}_{2} \mathrm{O}_{3}, \mathrm{NiO}$ and $\mathrm{TiO}_{2}$ ). While the high toxicity of the dissolvable ENMs $(\mathrm{CuO}, \mathrm{ZnO}$ ENMs) was attributed to their solubility, the authors found that the toxicity of less dissolvable ENMs depended on redox potential. That is, less dissolvable ENMs exhibited little or no toxicity when their Ec was outside the biological redox potential range ( -4.2 to $4.8 \mathrm{eV}$ ) but exhibited high toxicity if their Ec overlapped the biological redox potential (Zhang et al. 2012).

\section{Conclusion}

The effect of the aqueous medium on solubility is important in the context of reading across from bulk to nano-scale metal oxides. It is widely known that metal oxide solubility in water is very low (practically insoluble), and the present study (Table 3) confirms that water solubility of all three metal oxides would be classified as "low" $(\leq 1 \%)$ whether bulk or nano-scale was being considered. In DMEM, however, bulk versus nano-scale solubility varied depending on the metal oxide being investigated. While $\mathrm{NiO}$ and $\mathrm{TiO}_{2}$ displayed low solubility in DMEM (< $1.2 \%$ ) for both bulk and nano-scale forms, nano$\mathrm{CuO}$ had much higher solubility in DMEM than its bulk analogue (44.5\% compared with $1.17 \%$ respectively; Table 3). In other words, bulk $\mathrm{CuO}$ would not be a good model for nano-CuO due to the difference in dissolution behavior in cell culture medium. These observations show that, when evaluating ENM solubility for the purpose of read-across, it is important to test ENM solubility not only in water but also in biologically relevant media.

Consideration of aqueous medium is equally important for grouping ENMs according to solubility. In the present study, both nano-NiO and nano- $\mathrm{TiO}_{2}$ showed low or negligible solubility in both water and DMEM, but this was not the case for nano-CuO ENM, which was highly soluble in DMEM (11.8-44.5\%), but much less soluble in water $(0.99-3.31 \%)$. This result shows that grouping based on ENM dissolution in water may not reflect dissolution behavior in the biological medium selected to conduct toxicity assays.

The results also show the importance of evaluating the solubility of ENMs at concentrations that correspond to toxicity assays, for the purposes of read-across and grouping ENMs. When comparing solubility using a low initial concentration $(10 \mathrm{mg} /$ L) versus a high initial concentration $(100 \mathrm{mg} / \mathrm{L})$, dissolution behavior varied among the three metal oxide ENMs. In cell culture medium, both nano$\mathrm{CuO}$ and nano-NiO displayed increased solubility at the higher initial concentration by 3.8 -fold and 1.4-fold, respectively. In water however, this trend was reversed, with both nano- $\mathrm{CuO}$ and nano-NiO displaying increased solubility at the lower initial concentration by 3.3-fold and 1.2-fold, respectively. Nano- $\mathrm{TiO}_{2}$ behavior was notably different, however, in that nano- $\mathrm{TiO}_{2}$ concentration trends were the opposite of those displayed by nano$\mathrm{CuO}$ and nano-NiO. Specifically, in cell culture medium, nano- $\mathrm{TiO}_{2}$ displayed decreased solubility at the higher initial concentration (0.3-fold), whereas in water, nano- $\mathrm{TiO}_{2}$ displayed increased solubility at the higher initial concentration (5.5fold).

In summary, the new knowledge that these experiments have generated includes the influence of initial concentration on NP solubility; the reversal of these solubility/concentration trends from one metal oxide NP to another, and the over-riding influence of the aqueous medium on all these trends. These experimental results will inform future efforts to model the behavior of metal oxide ENMs in complex biological media, and will also inform the design of future toxicity assays, as the parameters precisely match the exposure conditions used for cellular toxicity assays which require DMEM, a widely used cell culture medium, at a typical exposure concentration of $10 \mathrm{mg} / \mathrm{L}$. The higher concentration of $100 \mathrm{mg} / \mathrm{L}$ was included for comparison as this is the concentration used in OECD solubility protocols that inform categorization and read-across exercises. This study demonstrated that ENM dissolution characteristics depend on the type of metal oxide, the aqueous medium being studied, and the initial concentration. The results emphasize the importance of evaluating the solubility of ENMs not only in water but also in biologically relevant fluids, when classifying ENMs 
according to solubility for the purpose of hazard assessment.

Acknowledgments Sincere thanks go to Dr. Sabina Halappanavar and Dr. Suzanne Beauchemin for their valuable review comments on an earlier version of the manuscript.

Funding information The study is financially supported by Health Canada's Chemicals Management Plan.

\section{Compliance with ethical standards}

Conflict of interest The authors declare that they have no conflict of interest.

Open Access This article is licensed under a Creative Commons Attribution 4.0 International License, which permits use, sharing, adaptation, distribution and reproduction in any medium or format, as long as you give appropriate credit to the original author(s) and the source, provide a link to the Creative Commons licence, and indicate if changes were made. The images or other third party material in this article are included in the article's Creative Commons licence, unless indicated otherwise in a credit line to the material. If material is not included in the article's Creative Commons licence and your intended use is not permitted by statutory regulation or exceeds the permitted use, you will need to obtain permission directly from the copyright holder. To view a copy of this licence, visit http://creativecommons.org/licenses/by/4.0/.

\section{References}

Adeleye AS, Conway JR, Perez T, Rutten P, Keller AA (2014) Influence of extracellular polymeric substances on the longterm fate, dissolution, and speciation of copper-based nanoparticles. Environ Sci Technol 48:12561-12568

Alkilany AM, Mahmoud NN, Hashemi F, Hajipour MJ, Farvadi F, Mahmoudi M (2016) Misinterpretation in nanotoxicology: a personal perspective. Chem Res Toxicol 29:943-948

Anderson W, Kozak D, Coleman VA, Jämting TK, Trau M (2013) A comparative study of submicron particle sizing platforms: accuracy, precision and resolution analysis of polydisperse particle size distributions. J Colloid Interface Sci 405:322330

Arts JHE, Hadi M, Irfan M, Keene AM, Kreiling R, Lyon D, Maier M, Michel K, Petry T, Sauer UG, Warheit D, Wiench K, Wohlleben W, Landsiedel R (2015a) A decision-making framework for the grouping and testing of nanomaterials (DF4nanoGrouping). Regul Toxicol Pharmacol 71:S1-S27

Arts JHE, Irfan M, Keene AM, Kreiling R, Lyon D, Maier M, Michel K, Neubauer N, Petry T, Sauer UG, Warheit D, Wiench K, Wohlleben W, Landsiedel R (2015b) Case studies putting the decision-making framework for the grouping and testing of nanomaterials (DF4nanoGrouping) into practice. Regul Toxicol Pharmacol 71:S1-S27
Avramescu M, Chénier M, Gardner HD, Rasmussen PE (2019) Solubility of metal oxide nanomaterials: cautionary notes on sample preparation. J Phys Conf Ser 1323:2001

Bove P, Malvindi MA, Kote SS, Bertorelli R, Summa M, Sabella S (2017) Dissolution test for risk assessment of nanoparticles: a pilot study. Nanoscale 9:6315-6326

Cho W, Duffin R, Howie SEM, Scotton CJ, Wallace WAH, MacNee W, Bradley M, Megson IL, Donaldson K (2011) Progressive severe lung injury by zinc oxide nanoparticles; the role of $\mathrm{Zn} 2+$ dissolution inside lysosomes. Part Fibre Toxicol 8:27

Cho W, Duffin R, Poland CA, Duschl A, Oostingh GJ, MacNee W, Bradley M, Megson IL, Donaldson K (2012) Differential pro-inflammatory effects of metal oxide nanoparticles and their soluble ions in vitro and in vivo; zinc and copper nanoparticles, but not their ions, recruit eosinophils to the lungs. Nanotoxicology 6:22-35

Chowdhury I, Hong Y, Walker SL (2010) Container to characterization: impacts of metal oxide handling, preparation, and solution chemistry on particle stability. Colloids Surf A Physicochem Eng Asp 368:91-95

Cohen J, Deloid G, Pyrgiotakis G, Demokritou P (2013) Interactions of engineered nanomaterials in physiological media and implications for in vitro dosimetry. Nanotoxicology 7:417-431

Decan N, Wu D, Williams A, Bernatchez S, Johnston M, Hill M, Halappanavar S (2016) Characterization of in vitro genotoxic, cytotoxic and transcriptomic responses following exposures to amorphous silica of different sizes. Mutat Res Genet Toxicol Environ Mutagen 796:8-22

Deloid GM, Cohen JM, Pyrgiotakis G, Demokritou P (2017) Preparation, characterization, and in vitro dosimetry of dispersed, engineered nanomaterials. Nat Protoc 12:355-371

Duffin R, Tran L, Brown D, Stone V, Donaldson K (2007) Proinflammogenic effects of low-toxicity and metal nanoparticles in vivo and in vitro: highlighting the role of particle surface area and surface reactivity. Inhal Toxicol 19:849-856

ECHA 2013 Assessing human health and environmental hazards of nanomaterials - best practice for REACH Registrants 2nd GAARN meeting. ECHA-13-R-04-EN, European Chemicals Agency (ECHA), Helsinki, Finland. In: . https:/echa.europa. eu/documents/10162/5399565/best_practices_human health_environment_nano_en.pdf/8e0adb6a-829c-43aa-84 c5-5361f8505996 2019

ECHA 2016 Usage of (eco)toxicological data for bridging data gaps between and grouping of nanoforms of the same substance. ED-02-16-228-EN-N, European Chemicals Agency, Joint Research Centre, Dutch National Institute for Public Health and the Environment. In: . https:/echa.europa. eu/documents/10162/13630/eco toxicological_for bridging_grouping_nanoforms_en.pdf 2019

Guggenheim EJ, Milani S, Röttgermann PJF, Dusinska M, Saout C, Salvati A, Rädler JO, Lynch I (2018) Refining in vitro models for nanomaterial exposure to cells and tissues. NanoImpact 10:121-142

Gunawan C, Teoh WY, Marquis CP, Amal R (2011) Cytotoxic origin of copper(II) oxide nanoparticles: comparative studies with micron-sized particles, leachate, and metal salts. ACS Nano 5:7214-7225

Hansen SF, Hjorth R, Skjolding LM, Bowman DM, Maynard A, Baun A (2017) A critical analysis of the environmental 
dossiers from the OECD sponsorship programme for the testing of manufactured nanomaterials. Environ Sci Nano 4: 282-291

Hansjosten I, Rapp J, Reiner L, Vatter R, Fritsch-Decker S, Peravali R, Palosaari T, Joossens E, Gerloff K, Macko P, Whelan M, Gilliland D, Ojea-Jimenez I, Monopoli MP, Rocks L, Garry D, Dawson K, Röttgermann PJF, Murschhauser A, Rädler JO, Tang SVY, Gooden P, Belinga-Desaunay M-A, Khan AO, Briffa S, Guggenheim E, Papadiamantis A, Lynch I, Valsami-Jones E, Diabaté S, Weiss C (2018) Microscopy-based high-throughput assays enable multi-parametric analysis to assess adverse effects of nanomaterials in various cell lines. Arch Toxicol 92:633-649

Hedberg J, Karlsson HL, Hedberg Y, Blomberg E, Odnevall Wallinder I (2016) The importance of extracellular speciation and corrosion of copper nanoparticles on lung cell membrane integrity. Colloids Surf B Biointerfaces 141:291-300

Hull M, Kennedy AJ, Detzel C, Vikesland P, Chappell MA (2012) Moving beyond mass: the unmet need to consider dose metrics in environmental nanotoxicology studies. Environ Sci Technol 46:10881-10882

ISO/TR 19057:2017 Nanotechnologies: Use and application of acellular in vitro tests and methodologies to assess nanomaterial biodurability. In: . https://www.iso. org/standard/63836.html?browse=tc

IZON Scientific How TRPS works. In: . https://izon.com/howtrps-works/ 2019

Jensen KA, Kembouche Y, Nielsen SH (2013) Towards a method for detecting the potential genotoxicity of nanomaterials. WP 4: Physicochemical Characterization of Manufactured Nanomaterials (MNs) and Exposure Media (EMs). Deliverable 4.7: Hydrochemical reactivity, solubility, and biodurability of NANOGENOTOX nanomaterials. Key intrinsic physicochemical characteristics of NANOGENOTOX nanomaterials. The National Research Centre for the Working Environment (NRCWE), Lersø Parkallé 105, DK2100 Copenhagen, DENMARK. . In: . https://www.anses. $\mathrm{fr} / \mathrm{en} / \mathrm{system} /$ files/nanogenotox deliverable.7.pdf 2019

Jeong J, Kim S, Lee S, Lee D, Han Y, Jeon S, Cho W (2018) Differential contribution of constituent metal ions to the cytotoxic effects of fast-dissolving metal-oxide nanoparticles. Front Pharmacol 9

Jiang J, Oberdörster G, Biswas P (2009) Characterization of size, surface charge, and agglomeration state of nanoparticle dispersions for toxicological studies. J Nanopart Res 11:77-89

Käkinen A, Kahru A, Nurmsoo H, Kubo A, Bondarenko OM (2016) Solubility-driven toxicity of $\mathrm{CuO}$ nanoparticles to Caco2 cells and Escherichia coli: effect of sonication energy and test environment. Toxicol Vitro 36:172-179

Karlsson HL, Cronholm P, Hedberg Y, Tornberg M, De Battice L, Svedhem S, Wallinder IO (2013) Cell membrane damage and protein interaction induced by copper containing nanoparticles - importance of the metal release process. Toxicology 313:59-69

Karlsson HL, Gliga AR, Calléja FMGR, Gonçalves CSAG, Wallinder IO, Vrieling H, Fadeel B, Hendriks G (2014) Mechanism-based genotoxicity screening of metal oxide nanoparticles using the ToxTracker panel of reporter cell lines. Part Fibre Toxicol:11

Koltermann-Jülly J, Keller JG, Vennemann A, Werle K, Müller P, Ma-Hock L, Landsiedel R, Wiemann M, Wohlleben W
(2018) Abiotic dissolution rates of 24 (nano)forms of 6 substances compared to macrophage-assisted dissolution and in vivo pulmonary clearance: grouping by biodissolution and transformation. NanoImpact 12:29-41

Krug HF (2014) Nanosafety research-are we on the right track? Angew Chem Int Ed 53:12304-12319

Landsiedel R, Ma-Hock L, Wiench K, Wohlleben W, Sauer UG (2017) Safety assessment of nanomaterials using an advanced decision-making framework, the DF4nanoGrouping. J Nanopart Res 19

Latvala S, Hedberg J, Di Bucchianico S, Möller L, Wallinder IO, Elihn K, Karlsson HL (2016) Nickel release, ROS generation and toxicity of $\mathrm{Ni}$ and $\mathrm{NiO}$ micro- and nanoparticles. PLoS ONE 11

Leitner J, Sedmidubský D, Jankovský O (2019) Size and shapedependent solubility of $\mathrm{CuO}$ nanostructures. Mater 12

Malvern Instruments Ltd (2019a) Dynamic light scattering common terms defined. Inform white paper MRK1764-01:2011. In: http://www.biophysics.bioc.cam.ac.uk/wpcontent/uploads/2011/02/DLS_Terms_defined_Malvern.pdf 2019

Malvern Instruments Ltd (2019b) Dynamic light scattering: an introduction in 30 minutes. Technical note MRK656-01: 2011. In: https://warwick.ac.uk/fac/cross $\mathrm{fac} / \mathrm{sciencecity/programmes/internal/themes/am} \overline{2}$ /booking/particlesize/intro_to_dls.pdf 2019

Midander K, Cronholm P, Karlsson HL, Elihn K, Möller L, Leygraf C, Wallinder IO (2009) Surface characteristics, copper release, and toxicity of nano- and micrometer-sized copper and copper(11) oxide particles: a cross-disciplinary study. Small 5:389-399

Minigalieva I, Bushueva T, Fröhlich E, Meindl C, Öhlinger K, Panov V, Varaksin A, Shur V, Shishkina E, Gurvich V, Katsnelson B (2017) Are in vivo and in vitro assessments of comparative and combined toxicity of the same metallic nanoparticles compatible, or contradictory, or both? A juxtaposition of data obtained in respective experiments with $\mathrm{NiO}$ and Mn3O4 nanoparticles. Food Chem Toxicol 109:393-404

Misra SK, Dybowska A, Berhanu D, Luoma SN, Valsami-Jones E (2012a) The complexity of nanoparticle dissolution and its importance in nanotoxicological studies. Sci Total Environ 438:225-232

Misra SK, Dybowska A, Berhanu D, Croteau MN, Luoma SN, Boccaccini AR, Valsami-Jones E (2012b) Isotopically modified nanoparticles for enhanced detection in bioaccumulation studies. Environ Sci Technol 46:1216-1222

Monteiller C, Tran L, MacNee W, Faux S, Jones A, Miller B, Donaldson K (2007) The pro-inflammatory effects of lowtoxicity low-solubility particles, nanoparticles and fine particles, on epithelial cells in vitro: the role of surface area. Occup Environ Med 64:609-615

Nel A, Xia T, Mädler L, Li N (2006) Toxic potential of materials at the nanolevel. Science 311:622-627

Oberdörster G, Kuhlbusch TAJ (2018) In vivo effects: methodologies and biokinetics of inhaled nanomaterials. NanoImpact 10:38-60

Odzak N, Kistler D, Behra R, Sigg L (2014) Dissolution of metal and metal oxide nanoparticles in aqueous media. Environ Pollut 191:132-138 
OECD 1995 (1995) Water Solubility,Test No. 105, Organisation for Economic Co-operation and Development (OECD), Paris, France

OECD 2002 (2002) Guidance document on transformation/ dissolution of metals and metal compounds in aqueous media. OECD SERIES ON TESTING AND ASSESSMENT number 29, Organisation for Economic Co-operation and Development (OECD), Paris, France

OECD 2012 (2012) Guidance on sample preparation and dosimetry for the safety testing of manufactured nanomaterials. Series on the safety of manufactured Nanomaterials no. 3, ENV/JM/MONO(2012)40, Organisation for Economic Cooperation and Development (OECD), Paris, France

OECD 2015 (2015) Considerations for using dissolution as a function of surface chemistry to evaluate environmental behaviour of nanomaterials in risk assessments. A preliminary case study using silver nanoparticles; Series on the safety of manufactured Nanomaterials, no. 62, ENV/JM/ MONO(2015)44, Organisation for Economic Co-operation and Development (OECD), Paris, France

OECD 2017 (2017) Dispersion stability of nanomaterials in simulated environmental media. Test no. 318. Organisation for Economic Co-operation and Development (OECD), Paris, France

OECD 2018 (2018) Assessment of biodurability of nanomaterials and their surface ligands; series on the safety of manufactured nanomaterials no. 86, ENV/JM/MONO(2018)11, Organisation for Economic Co-operation and Development (OECD), Paris, France 2018

Pal AK, Aalaei I, Gadde S, Gaines P, Schmidt D, Demokritou P, Bello D (2014) High resolution characterization of engineered nanomaterial dispersions in complex media using tunable resistive pulse sensing technology. ACS Nano 8: 9003-9015

Peng C, Shen C, Zheng S, Yang W, Hu H, Liu J, Shi J (2017) Transformation of $\mathrm{CuO}$ nanoparticles in the aquatic environment: influence of $\mathrm{pH}$, electrolytes and natural organic matter. Nanomaterials 7

Rahman L, Wu D, Johnston M, William A, Halappanavar S (2017) Toxicogenomics analysis of mouse lung responses following exposure to titanium dioxide nanomaterials reveal their disease potential at high doses. Mutagenesis 32:59-76

Semisch A, Ohle J, Witt B, Hartwig A (2014) Cytotoxicity and genotoxicity of nano - and microparticulate copper oxide: role of solubility and intracellular bioavailability. Part Fibre Toxicol 11:10

Sohal IS, Cho YK, O'Fallon KS, Gaines P, Demokritou P, Bello D (2018) Dissolution behavior and biodurability of ingested engineered nanomaterials in the gastrointestinal environment. ACS Nano 12:8115-8128

Strauch BM, Hubele W, Hartwig A (2020) Impact of endocytosis and lysosomal acidification on the toxicity of copper oxide nano-and microsized particles: uptake and gene expression related to oxidative stress and the DNA damage response. Nanomaterials: 10

Studer AM, Limbach LK, Van Duc L, Krumeich F, Athanassiou EK, Gerber LC, Moch H, Stark WJ (2010) Nanoparticle cytotoxicity depends on intracellular solubility: comparison of stabilized copper metal and degradable copper oxide nanoparticles. Toxicol Lett 197:169-174

Taurozzi JS, Hackley VA, Wiesner MR (2011) Ultrasonic dispersion of nanoparticles for environmental, health and safety assessment issues and recommendations. Nanotoxicology 5: 711-729

Taurozzi JS, Hackley VA, Wiesner MR (2013) A standardised approach for the dispersion of titanium dioxide nanoparticles in biological media. Nanotoxicology 7:389-401

Wang Z, Von Dem Bussche A, Kabadi PK, Kane AB, Hurt RH (2013) Biological and environmental transformations of copper-based nanomaterials. ACS Nano 7:8715-8727

Wang D, Lin Z, Wang T, Yao Z, Qin M, Zheng S, Lu W (2016) Where does the toxicity of metal oxide nanoparticles come from: the nanoparticles, the ions, or a combination of both? J Hazard Mater 308:328-334

Wohlleben W, Ma-Hock L, Boyko V, Cox G, Egenolf H, Freiberger H, Hinrichsen B, Hirth S, Landsiedel R (2013) Nanospecific guidance in REACH: a comparative physicalchemical characterization of 15 materials with methodical correlations. J Ceram Sci Technol 4:93-104

Yamada M, Takahashi S, Sato H, Kondo T, Kikuchi T, Furuya K, Tanaka I (1993) Solubility of nickel oxide particles in various solutions and rat alveolar macrophages. Biol Trace Elem Res 36:89-98

Zhang H, Ji Z, Xia T, Meng H, Low-Kam C, Liu R, Pokhrel S, Lin S, Wang X, Liao Y, Wang M, Li L, Rallo R, Damoiseaux R, Telesca D, Mädler L, Cohen Y, Zink JI, Nel AE (2012) Use of metal oxide nanoparticle band gap to develop a predictive paradigm for oxidative stress and acute pulmonary inflammation. ACS Nano 6:4349-4368

Publisher's note Springer Nature remains neutral with regard to jurisdictional claims in published maps and institutional affiliations. 